positive iodine, yielding the unstable solute, the phenyl-iodoxylate of the alkali metal:

$$
\begin{aligned}
& \mathrm{C}_{6} \mathrm{H}_{5} \mathrm{IO}_{2}+\mathrm{Na}+(\mathrm{OH})-\longrightarrow \mathrm{Na}+\left[\mathrm{C}_{6} \mathrm{H}_{5} \mathrm{IO}_{3} \mathrm{H}\right]- \\
& \begin{array}{l}
\text { Iodoxy- } \\
\text { benzene }
\end{array}+\underset{\text { hydroxide }}{\text { Sodium }}=\quad \begin{array}{c}
\text { Sodium } \\
\text { phenyl-iodoxylate }
\end{array}
\end{aligned}
$$

Nitrobenzene, for the reason explained above, does not combine with alkali ; but the arylphosphonic and arsonic acids are probably analogous to the iodoxylates.

When the solution of an alkaline iodoxylate is boiled, its complex negative ion extrudes the group $\mathrm{IO}_{3}$ which, as the iodate ion, carries off the ionic charge, leaving behind benzene:

$$
\mathrm{C}_{6} \mathrm{H}_{5} \mathrm{IO}_{8} \mathrm{H}^{\prime} \longrightarrow \mathrm{IO}_{3}{ }^{\prime}+\mathrm{C}_{6} \mathrm{H}_{6} .
$$

This elimination of the iodate ion is characteristic of such substances, especially in alkali. Thus, in a cold iodoxylate solution, the complex ion spontaneously co-operates with dissolved iodoxybenzene to do so, and the residues couple to form diphenyliodyl hydroxide (or its alkali salt), with the structure of which one may compare the diaryl phosphinic and arsinic acids:

$$
\mathrm{PhIO}_{2}+\mathrm{PhIO}_{3} \mathrm{H}^{\prime} \longrightarrow \mathrm{IO}_{3}{ }^{\prime}+\mathrm{Ph}_{2} \mathrm{IO} . \mathrm{OH} .
$$

Again, the same dominant tendency is seen in the formation of iodonium compounds by Victor Meyer and Hartmann's second method, where iodoso- and iodoxy-compound react together in an alkaline medium :

$$
\mathrm{RIO}_{2}+\mathrm{RIO} \longrightarrow \mathrm{IO}_{3}{ }^{\prime}+\mathrm{R}_{2} \mathrm{I} .
$$

The converse of these processes, that is, the return of iodine from inorganic iodate into the organically combined state, proves easy to realize in the laboratory, under conditions of high acidity, organic derivatives of multivalent iodine being formed.

It will be understood that in these examples of reactions (all of which, in the discourse of which this is a condensation, were illustrated by working scale-models showing the atomic and electrical exchanges), the detailed intermediate mechanisms have here been slightly simplified, especially as regards the organic parts of the groups concerned. In them, however, the primary point is rather the formation and existence of hitherto unknown types of iodine compounds. These lead to a new field of chemical inquiry, and help to show, as do the biochemical facts reviewed, that we must think of iodine as an element which, like nitrogen or arsenic, is not inorganic alone, but is emphatically an organic element also.

\title{
Scientific Research in India
}

\section{From a Correspondent}

$\mathrm{T}$ HE activities of the scientific delegation in India were by no means confined to the proceedings of the Congress in Calcutta and to sightseeing. Every opportunity was taken by individual members or groups of members to inform themselves of the progress of science in the various institutions which occasion could be made to visit. The notes which follow cannot be exhaustive, as they are based upon information only from members of the party who have just returned to England in the S.S. Strathaird; a substantial number of the delegates are not yet home.

The discovery of the pre-Aryan civilization of the Indus basin has stimulated studies in Indian archæology, and the delegation was profoundly impressed by the care bestowed upon the famous frescoes and sculptures in the rock-hewn temples at Ajanta and Ellora, while excavation is in progress elsewhere in the dominions of H.E.H. the Nizam of Hyderabad. The museums at Delhi, Bombay, Sarnath (near Benares), Calcutta and Madras all possess notable treasures, and that at
Calcutta especially needs much greater space for its adequate exposition in order to guide future excavation. Turning to work within the scope of present-day anthropology, the Brahmachariya Sangha founded by the late Maharajah of Kazimbazar illustrates a type of Indian organization designed to help especially aboriginal peoples to overcome handicaps due to lack of knowledge of Hindu or Dravidian languages and to general backwardness. The aborigines around Ranchi on the Chota Nagpur plateau are being taught on the basis of a modernist interpretation of the Vedas, and schools, clinics and legal aid come within the province of this organization.

Elsewhere, the great medical institutions naturally attracted attention. At the famous Haffkine Institute in Bombay special note was taken of the work in progress towards a theory as to outbreaks of plague after periods of immunity; it was learned incidentally that mice are found more suitable than rats for plague experimentation. The work on rabies was also remarked; and it was 
observed that in Bombay malaria has been reduced to almost negligible proportions by covering in all open water tanks with fine-meshed wire netting or with glass. The School of Tropical Diseases at Calcutta is worked in connexion with the hospital, where there are beds for keeping cases under prolonged study and treatment. The All India Institute of Hygiene and Public Health possesses fine premises, but there appears as yet to be a shortage of expert workers ; and it may be remarked here that a more extensive supply of current medical and scientific journals, English and foreign, is apparently needed in medical libraries. It was satisfactory to note the increasing number of women's hospitals, staffed by women, especially in such a land as India, where so many women are debarred from medical aid unless rendered by their own sex. Women doctors are increasing in number, but an adequate supply of good nurses is as yet far from assured. Medical psychology was found to be fairly well established in Calcutta, and an excellent general and educational psychology is rapidly gathering strength in Mysore. The value of industrial psychology is well recognized; the material aspects of the science appear to outweigh the purely philosophical.

Research in agriculture, obviously of outstanding importance for India, aroused much interest. For example, at the Imperial Agricultural Research Institute in New Delhi, the results were exhibited of crossing the sugar-cane with a species of bamboo which grows to a height of 60 feet, and also with sorghum and Indian corn. This work forms a part of breeding experiments carried out in order to discover the origin of cultivated sugar-canes and to improve them by hybridization. In the chemical department of the Institute valuable work is in progress on the utilization of atmospheric nitrogen in soils. The visit to Dehra Dun gave the delegates opportunity to see something of the important work of the Forest Research Institute, in which departments are concerned not only with the problems of forestry itself but also with timber testing and preservation and the uses of woodpulp, resins and other products. The Punjab Agricultural College and Research Institute afforded an opportunity for observing the progress of valuable economic research in various departments, which has already added much to the agricultural wealth of the province. At the University of Agra the dissemination of cereal rust fungi has been under investigation for seven years, and the foci of infection have been traced to hill-tracts where rusts remain during summer in the uredo-stage. The good work of the cotton research and textile research laboratories is well known, and in consequence the opportunity of seeing some of the results at Bombay was welcomed.
Plant virus work on tobacco leaf curl and on mosaic of sugar-cane was found to be in progress at more than one centre, but none was encountered on potato virus diseases, though preparations are being made at New Delhi for a general assault on these problems by genetic methods. In connexion with animal husbandry, one of the delegates comments in the highest terms upon the work of the Indian veterinary colleges and the cattle and other breeding establishments which he was enabled to visit. In the notes of another delegate reference is made to a secondary school at Bikram, a village south of Patna, which possesses a demonstration farm partly worked by pupils in the agricultural class; the principle appears capable of wider application.

Delegates were fortunate in being able to take part in the hundred and fiftieth anniversary of the foundation of the Calcutta Botanic Gardens, which have been directed by so distinguished a succession of botanists and have played so important a part in the development of systematic botany. The small aquarium at Madras, the extension of which is contemplated, was much admired for the interest of some of its special exhibits, for example, the sea-snakes. Some adverse comment was directed against the attendants, whose artificial stimulation of the exhibits for the entertainment of visitors was deprecated. The zoological garden at Mysore was particularly noteworthy for the care bestowed on its lay-out and upkeep and for the fine and happy condition of the inmates. It was noticed that the enclosure of the giraffes by a small ditch and a single rail about eight feet above ground seemed entirely adequate.

It is well known that the Geodetic Survey has its headquarters for mapping and fieldwork at Dehra Dun; but reference is due here to the latitude variation station at Agra which, it is hoped, will prove to be more free from causes of systematic errors than the station previously at Dehra Dun, which suffered from poor conditions for observation owing to its nearness to the Himalayas.

It is not the object of this report to comment further upon the work of the research departments and institutions so long associated with the Governments of India; nor can it be attempted to review all, or even any large fraction, of the work of the various universities visited by the delegation. But special reference has been made by one of the delegates to the important applications of science to industry under investigation in the chemical laboratory at the University of Lahore, which are directed primarily to the utilization of waste products. Thus, cottons are improved in appearance by treatment with colloidal solutions of certain silk-like cotton wastes, 
resins are recovered from oil residues, soaps are made stable in colour and perfume, waste molasses is made into tiles and insulating materials, broken rice grains of little or no value are changed into colloidal solutions and used for making synthetic rice grains, oils are purified so as to burn without smoking. Researches of a fundamental character are being made into the magnetic properties of atoms and molecules with the object of revealing the nature of chemical bonds and the control of chemical reactions. At the Tata Institute at Bangalore the experiments in the physics section on backward internal scattering of light in liquids and the effect of supersonic waves on refraction show a combination of high experimental skill and first-class apparatus. A demonstration of the structure of lustrous shells was beautiful and impressive.

Among other notes, one of the delegates was struck with the initiative shown in making apparatus, which otherwise would have been hard to come by in India, at the Central Meteorological

\section{The Aurora of}

$\mathrm{T}$ HE auroral display on the night of January 25-26 was remarkable not only for its brilliance but also for the wide area over which it was observed. Some time must elapse before it is possible to collect complete information, but it seems certain, from the newspaper reports already published, that it was seen over practically the whole of Europe, and as far south as Gibraltar and Sicily. The Times of January 27 states also that vivid auroral displays were seen over a large part of Canada on the nights of January 24-25 and 25-26.

Accounts of the phenomenon as observed in the British Isles differ considerably in points of detail. It is proposed to give here a few extracts from the most precise reports received either by NATURE or by the Meteorological Office. An account of the appearances observed at Harpenden, Herts, by Dr. B. A. Keen was given in last week's issue. Dr. Keen observed the display from 6.45 until after midnight. Three periods of brilliant display were noted, around $7.45,8.30$ and 9.45. The main features noted were red glows in the northwest and north-east, with a low green arc between during the early stages, green and white rays traversing a bright red glow in the north-north-east about 7.45, and rapidly fluctuating green streamers between north-west and north-east about 9.45 .

At Kew Observatory, detailed observations were made between 6.50 and 9.10. These observations show good general agreement with those made by Dr. Keen, except that a green coloration of the
Station for altitude observations in Agra. Another comments upon the fine work of the Hydrodynamic Research Station at Poona, where, beneath the great irrigation dam, large-scale experiments are possible and have resulted in numerous and various records covering the work of years and published by the Government of India, but yet to be incorporated, as they should be, in text-books on hydraulics.

Such are a few examples and it must be emphasized that they are only a few among many

of the widespread and practical interest in the advancement of science and its applications encountered by the delegation in India. If the delegation, through the contacts which its members have made, has succeeded on one hand in aiding that advancement in any manner, and should succeed, on the other hand, in broadening understanding at home of the achievements of scientific workers in India, it will have discharged its most important functions for the benefit of science in both countries.

\section{January $25-26$}

arcs and rays is not mentioned. Strong groups of coloured rays were observed after 7.35 , and at 7.51 these were spreading out from north-northeast to west-north-west reaching elevations of $5^{\circ}$ to $10^{\circ}$ above Polaris. At 7.57 the glow extended slightly beyond the zenith. A few minutes later, at 8.07, the display faded completely and no aurora was visible for several minutes. The later stages as observed at Kew were distinctly less brilliant, though there were some further appearances of arcs, patches and rays.

Mr. Charles Leaf sends details of observations made near Cambridge from 1.15 on January 26. He writes as follows:

"As seen at 1.15 G.M.T. there was a bright greenish glow behind banded cirrus cloud right across the northern horizon, while just to the north-west of the-zenith there were two parallel bands of delicate pinkish light. Short groups of rays frequently developed in these bands. The rays were paler than the bands themselves, and gave the impression that they were white rays showing through the bands. The pink coloration gradually spread across the zenith towards the south-east where it appeared as a darker red patch, due to the background not being illuminated. At the same time there appeared a few faint luminous marks to the north-east, again quite close to the zenith. By 1.35 all that remained was a much fainter glow to the north and north-west, and this persisted until 2.30 , when I went to bed."

A letter received in the Meteorological Office 